\title{
Blood-flow pulsatility variation along the carotid artery including crossing the extracranial- intracranial border
}

UMC Utrecht

Rick J van Tuijl ${ }^{1}$, Birgitta K Velthuis ${ }^{1}$, Ynte M Ruigrok ${ }^{2}$, Irene C van der Schaaf ${ }^{1}$, Jaco J M Zwanenburg ${ }^{1}$

1) Department of Radiology, University Medical Center Utrecht, the Netherlands

2) Department of Neurology and Neurosurgery, Rudolf Magnus Institute of Neuroscience, University Medical Center Utrecht, the Netherlands

\begin{abstract}
Background and purpose:
- Previous studies ${ }^{1,2}$ reported attenuation of arterial flow pulsation over the carotid siphon part the internal carotid artery (ICA).

- We aimed to confirm these results and further extend them by assessing the extracranial part of the ICA and by assessing the carotid distensibility by measuring the lumen Area Index (AI).

- The influence of age and sex on pulsatility and diameter distensibility, and the damping factor were also investigated.
\end{abstract}

\section{Results:}

- Reduction of PI measured between the $\mathrm{C} 4$ and $\mathrm{C} 7$ was significant $\left(8.3 \%, P=7.2^{*} 10^{-7}\right)$ but between extracranial $\mathrm{C} 1$ - and intracranial C7 was small and not significant $(1.8 \%, \mathrm{P}=0.14)$.

- The distensibility significantly decreased from $\mathrm{C} 1$ to $\mathrm{C} 4$, and significantly increased from C4 to C7.

- The reported $\mathrm{PI}$ and $\mathrm{Al}$ trend per vessel over the $\mathrm{C} 1, \mathrm{C} 4$, and C7 segments was consistently seen in $95 \%$ of the evaluated vessels.

- Damping over the carotid siphon significantly $\left(P=2.1^{*} 10^{-5}\right)$ decreases with increasing age similarly for both sexes.

\begin{tabular}{|ccccc|} 
ROI & Vessel & $\begin{array}{c}\text { Gender } \\
(\mathrm{M} / \mathrm{F})\end{array}$ & PI & Al \\
\hline C1 & Right ICA & $\mathrm{M}$ & $0.97 \pm 0.09$ & $0.18 \pm 0.03$ \\
\hline & & $\mathrm{F}$ & $0.83 \pm 0.10$ & $0.18 \pm 0.06$ \\
\hline C4 & Right ICA & $\mathrm{M}$ & $1.04 \pm 0.08$ & $0.11 \pm 0.03$ \\
\hline & & $\mathrm{F}$ & $0.90 \pm 0.11$ & $0.12 \pm 0.03$ \\
\hline C7 & Right ICA & $\mathrm{M}$ & $0.94 \pm 0.10$ & $0.30 \pm 0.08$ \\
\hline & & $\mathrm{F}$ & $0.82 \pm 0.12$ & $0.29 \pm 0.07$ \\
\hline & & & & \\
\hline C1 & Left ICA & $\mathrm{M}$ & $0.99 \pm 0.13$ & $0.17 \pm 0.06$ \\
\hline & & $\mathrm{F}$ & $0.82 \pm 0.10$ & $0.17 \pm 0.04$ \\
\hline C4 & Left ICA & $\mathrm{M}$ & $1.07 \pm 0.18$ & $0.12 \pm 0.05$ \\
\hline & & $\mathrm{F}$ & $0.89 \pm 0.08$ & $0.10 \pm 0.03$ \\
\hline C7 & Left ICA & $\mathrm{M}$ & $0.98 \pm 0.16$ & $0.29 \pm 0.09$ \\
\hline & & $\mathrm{F}$ & $0.80 \pm 0.11$ & $0.29 \pm 0.06$ \\
\hline
\end{tabular}

Table 1: $P I$ and Al for both male and female values: mean $\pm S D$.

\section{Interpretations:}

- The addition of extracranial measurements and distensibility measurements suggest a more complicated behavior than just damping caused by the carotid siphon.

- The bony carotid canal seems to locally limit the distensibility of the ICA, thus increasing the flow pulsatility at $\mathrm{C} 4$.
Material and methods:

- Blood-flow pulsation was assessed using 2D PC-MRI at 3T (Philips) in 68 healthy volunteers.

- Pulsatility Index (PI) and Al were calculated from blood-flow velocities and number of voxels measured at the extracranial C1, carotid canal C4, and intracranial C7 segments of the ICA as defined by Bouthillier ${ }^{3}$.

- The damping factor ([PI at C4]/[PI at C7]) was calculated to illustrate the effect of age and sex on damping across the carotid siphon.

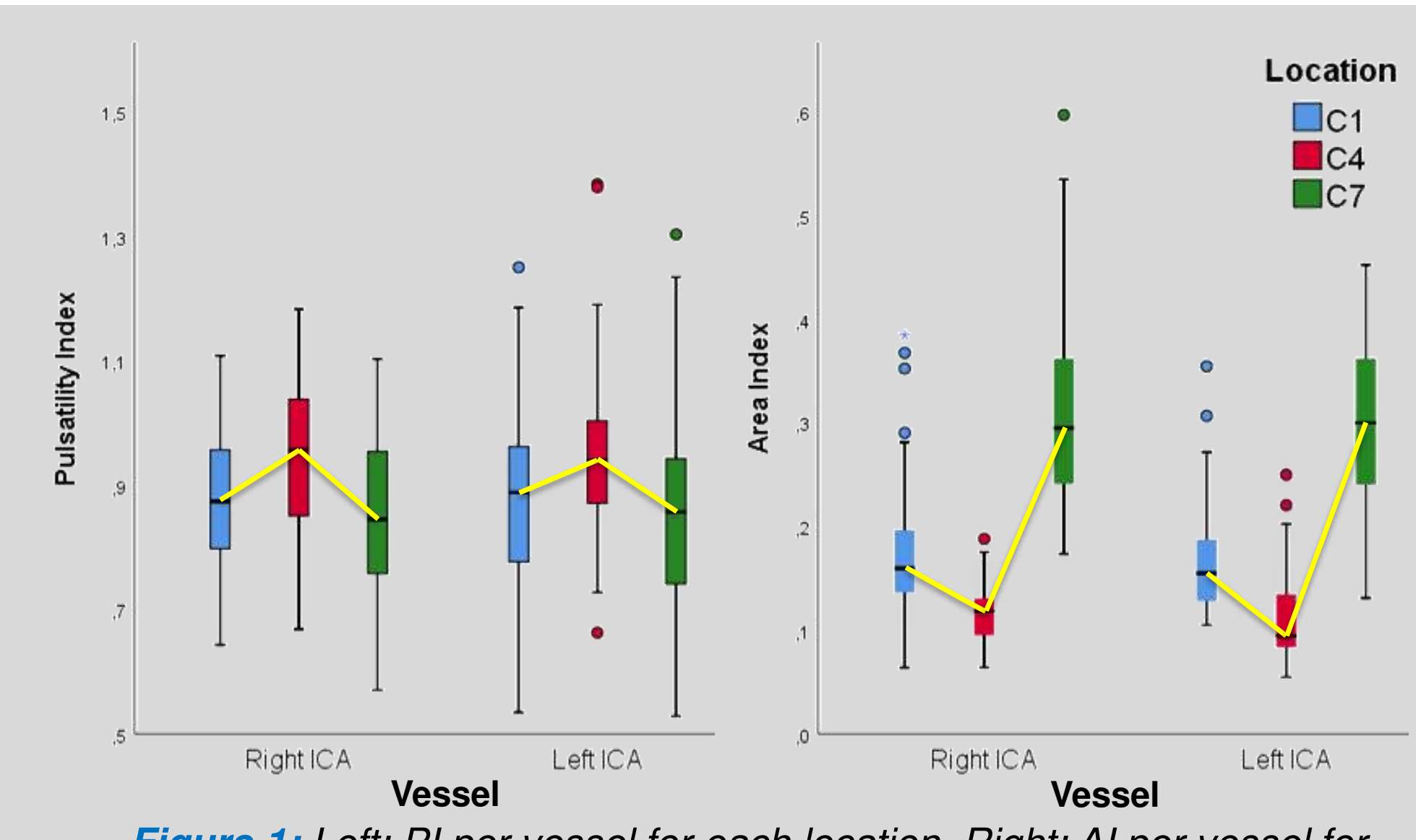

Figure 1: Left: PI per vessel for each location. Right: Al per vessel for each location.

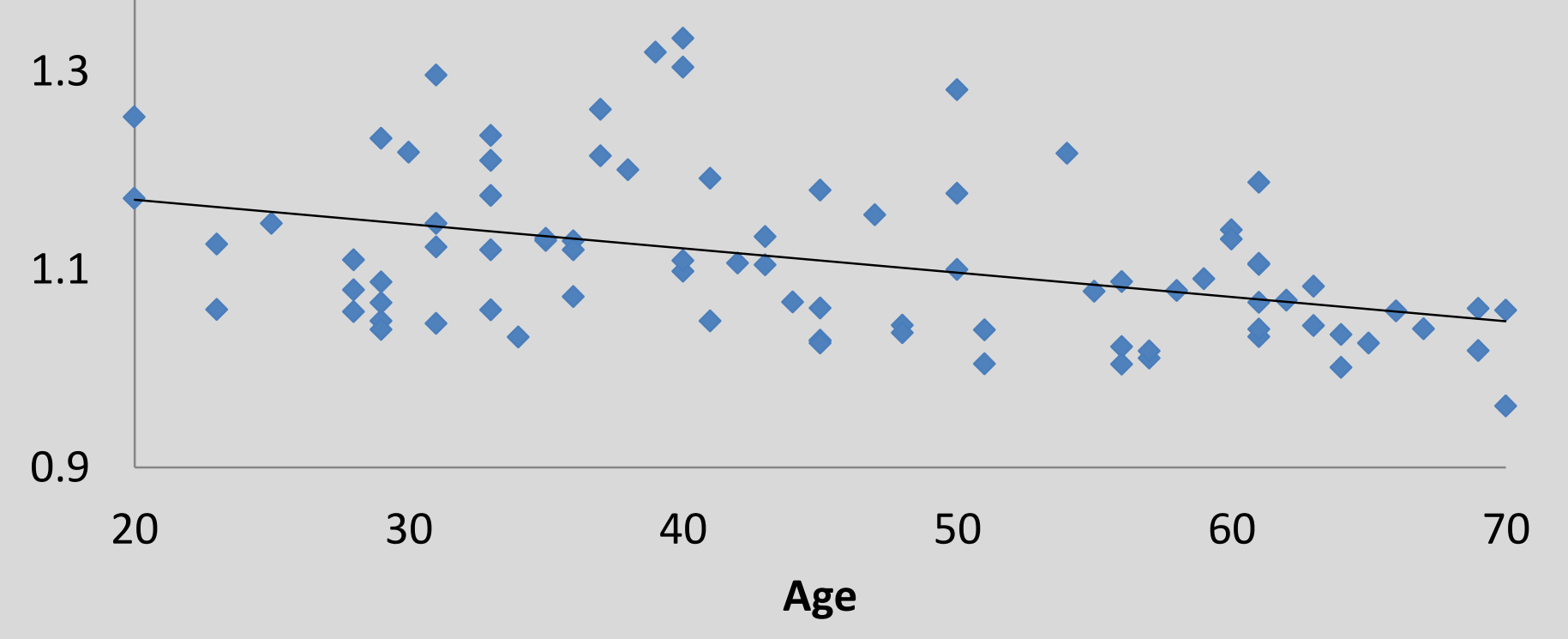

Figure 2: Damping Factor over age for all subjects.

\section{Conclusions:}

- The PI patterns confirmed previous studies: PI significantly reduces over the carotid siphon between $\mathrm{C} 4$ and $\mathrm{C} 7$ location. $\mathrm{PI}$ reduction from extra- to intracranial $(\mathrm{C} 1-\mathrm{C} 7)$ is not significant.

- Men have a significantly higher PI compared to women for all three ICA locations. 